\title{
gibalt.
}

Seite

gbthrzungen . . . . . . . . . . . . . . . . . . . . . . 7

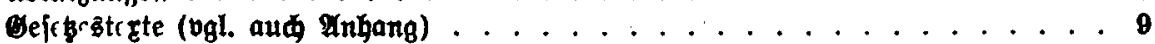

1. $\$$ - difloronung ....................... 8

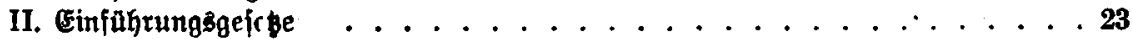

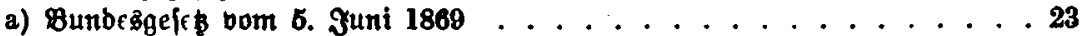

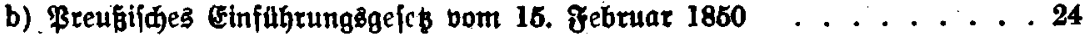

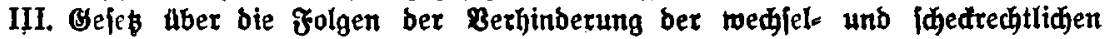
Đanblungen im Gualanb bom 13. Ipril $1914 \ldots \ldots$

IV. Beroronung zum Shuße gegen bie Stülegung von Bantbetrleben vom 19. Upril 1919 . . . . . . . . . . . . . . . . . . . . . 25

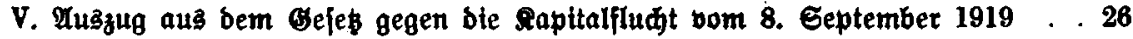

\section{Allucmrine Cinlritung.}

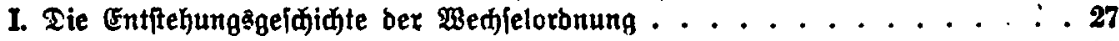

11. Tie Quellen bes æedfelredts und ihre Mangorbnung . . . . . . . . . . . 28

III. Die Entftehung ber ßeđfelverpfliđtung . . . . . . . . . . . . . . 29

IV. Die binalichen Fedite im $\mathfrak{B e c h i e l ~ . ~ . ~ . ~ . ~ . ~ . ~ . ~ . ~ . ~ . ~ . ~ . ~ . ~ . ~ . ~} 30$

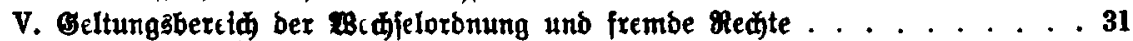

Wrafelordnang.

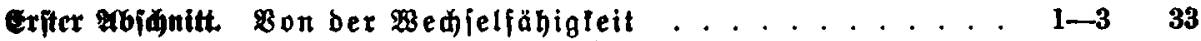

3wetter abjuitt. Bon gezogenen $\mathfrak{B}$ edjeln:

1. Erfordemiffe eines gezogenen \$edjels. . . . . . . . . . . . . . . 4-7 42

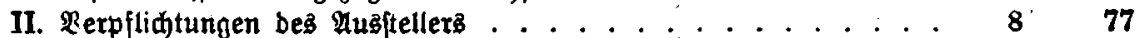

111. Inboffament . . . . . . . . . . . . . . . . . . . . . . 9-17 80

IV. Bröfentation zur Ynnahme . . . . . . . . . . . . . . 18-20 108

V. Innahme (Alzeptation). . . . . . . . . . . . . . . . . 21-24 114

V1. Renteb auf Gidexịtellung:

1. Wegen niळt erhaltener Innahme . . . . . . . . . . . . . . 25-28 128

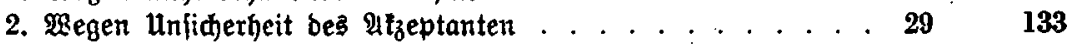

VII. Erffullung ber $\mathfrak{B e d f e l b e r b i n b l i d ) t e i t : ~}$

1. Bahlungatng . . . . . . . . . . . . . . . . 30-35 138

2. Baflung ....................... . . . $36-40143$

VIII. Regré̉ mangels Bahlung . . . . . . . . . . . . . . . . . 41-55 160

IX. Interbention:

1. (5hrenannnhme................... 56-61 189

2. (Ehtenzahlung ................... 62-65 197

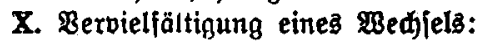

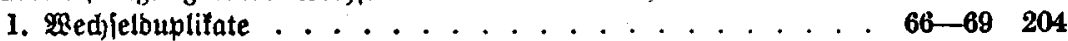

2. Sedjeltopien ................ . . 70-72 212

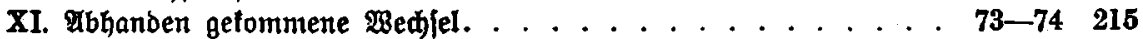

XII. Falíde $\mathfrak{B e c h l e l ~ . ~ . ~ . ~ . ~ . ~ . ~ . ~ . ~ . ~ . ~ . ~ . ~ . ~ . ~ . ~ . ~ . ~ . ~ . ~ 7 5 - 7 6 ~} 229$

X111. $\mathfrak{B}$ edjelverjährang . . . . . . . . . . . . . . . . . . . . . 77-80 234 


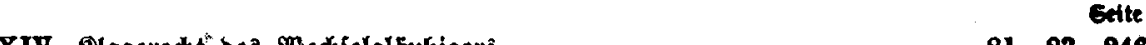

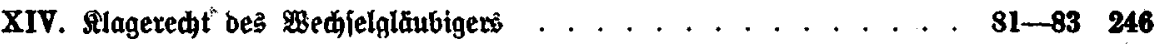

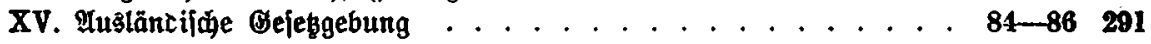

XVI. Broteft ....................... 87-90 298

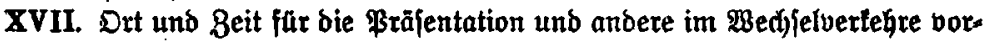
tommente Đandlungen .............. 91-93 336

XVIII. Mangelijafte Unteridriften . . . . . . . . . . . . . . . . . 91-95 349

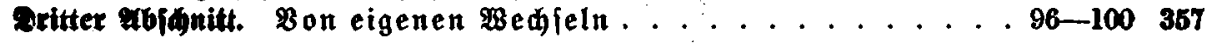

Anhang.

1. Gefez, betreffend bie Erleichtenung bes

II. Betanntmaduntg, betreffend bie Erthebung von Wedjel- und Sdhedprotepten Durd Boftbeamte. Bom 5. Auguft $1908 \ldots \ldots . \ldots \ldots 7$

III. $\mathfrak{A} u$ ş子

IV. Brotefformulare aนs ber Dienftantwcifung für ben \$oftproteft ......373

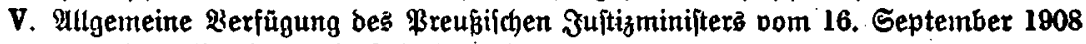

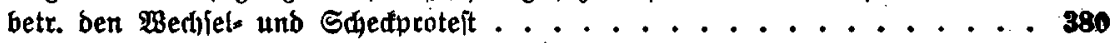

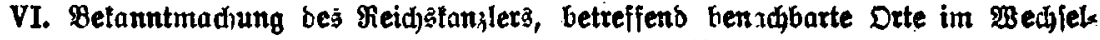

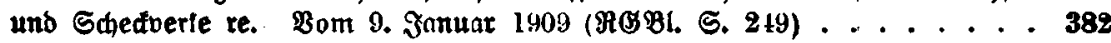

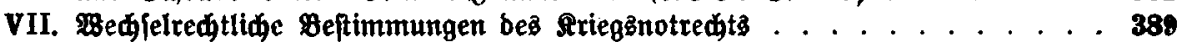

miphabetildes Regifter. . . . . . . . . . . . . . . . . . . 400 